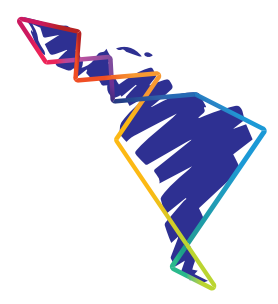

\title{
Desaparición forzada en la jurisprudencia de la Corte Europea de Derechos Humanos: análisis de casos
}

\author{
Forced Disappearance in the \\ Jurisprudence of the European Court \\ of Human Rights: Case Analyses
}

\section{Desaparecimento forçado na jurisprudência da Corte Europeia de Direitos Humanos: análise de casos}

\author{
Sebastián De León González ${ }^{1}$ \\ Diana Carolina Villa²
}

\section{Resumen}

En este artículo se presenta el análisis realizado a 24 sentencias de la Corte Europea de Derechos Humanos sobre casos de desaparición forzada de personas como aporte al marco jurídico internacional. Se decidió usar una serie de indicadores que permitieron comparar las diversas interpretaciones que ha hecho la Corte frente a las vulneraciones de derechos humanos, se prestó especial atención a los instrumentos internacionales que ha utilizado el alto Tribunal para abordar los casos de desaparición forzada, los factores temporales, espaciales y circunstanciales en los cuales se desarrolló la comisión del delito, la vulneración específica de derechos y la definición que asume el órgano jurisdiccional sobre este fenómeno.

Palabras clave: Convenio Europeo de Derechos Humanos, Corte Europea de Derechos Humanos, desaparición forzada, instrumentos internacionales

1 Estudiante de Derecho y miembro del grupo de investigación Horizonte Autónomo de la Universidad Autónoma de Colombia. Orador y semifinalista del XV Concurso Universitario de Derechos Humanos organizado por la Defensoría del Pueblo en Colombia, Reconocimiento especial por parte de la Universidad Autónoma de Colombia.

2 Abogada, especialista en Derecho Penal y Justicia Transicional, candidata a Magister en Ciencias Penales y Forenses por la Universidad Autónoma de Colombia. Coordinadora del semillero de investigación Horizonte Autónomo. 


\section{Summary}

This article presents the analysis of 24 court sentences of the European Court of Human Rights on cases of forced disappearance of people as a contribution to the international legal framework. It was decided to use a series of indicators that made it possible to compare the various interpretations that the Court has made regarding human rights violations, paying special attention to the international instruments used by the High Court to deal with cases of forced disappearance; temporary, spatial and circumstantial factors in which the commission of the offense was developed, the specific violation of rights and the definition assumed by the jurisdictional body on this phenomenon.

Keywords: European Convention on Human Rights, European Court of Human Rights, Forced disappearance, International instruments

\section{Resumo}

Este artigo apresenta a análise realizada a 24 sentenças da Corte Europeia dos Direitos Humanos sobre casos de desaparecimento forçado de pessoas como contribuição ao marco jurídico internacional. Decidiu-se utilizar uma série de indicadores que permitiram comparar as diversas interpretações que a Corte fez a respeito às vulnerações de direitos humanos, prestando especial atenção aos instrumentos internacionais utilizados pelo Alto Tribunal para abordar os casos de desaparecimento forçado; os fatores temporais e circunstanciais nos quais se desenvolveu a comissão do delito, a vulneração específica de direitos e a definição assumida pelo órgão jurisdicional sobre este fenômeno.

Palavras-chave: Convenio Europeu de Direitos Humanos, Corte Europeia de Direitos Humanos, Desaparecimento forçado, Instrumentos internacionais

\section{Introducción}

Los análisis que se presentan en este artículo corresponden a los avances del proyecto de investigación "Desaparición Forzada de personas: análisis de los instrumentos internacionales y su aplicación frente al posacuerdo en Colombia”, desarrollada en la Universidad Autónoma de Colombia como aporte al marco jurídico internacional ${ }^{3}$.

Se analizaron 24 sentencias de la Corte Europea de Derechos Humanos (en adelante ECHR, la Corte o el alto Tribunal), haciendo énfasis en la posición del alto Tribunal frente a la vulneración de Derechos, al concepto de desaparición forzada,

3 Este artículo forma parte del avance realizado por los autores Sebastián De León y Diana Carolina Villa en el proyecto de Investigación "Desaparición forzada de personas: análisis de los instrumentos internacionales y su aplicación frente al posacuerdo en Colombia" dirigido por Deissy Motta Castaño PhD., en Procesos Sociales y Políticos de América Latina por la Universidad de Artes y Ciencias Sociales de Santiago de Chile, docente de Derechos Humanos, directora e investigadora principal del proyecto y directora del Semillero de investigación Horizonte Autónomo de la Universidad Autónoma de Colombia, a ella nuestro más sincero agradecimiento por todo el apoyo brindado. 
los factores temporales, espaciales o circunstanciales en que se ha cometido el delito, y a los instrumentos internacionales aplicados en los casos donde se ha presentado este fenómeno. Es importante aclarar que este artículo no recoge los casos de Bosnia durante la guerra civil, ya que dichos casos, pese a originarse en el contexto Europeo, no hacen parte del compendio Jurisprudencial de la ECHR.

La comisión de delitos de desaparición forzada es un fenómeno relativamente nuevo para el Sistema Europeo de Derechos Humanos, pero ha sido recurrente en el contexto interamericano y en el caso particular de Colombia es uno de los factores importantes que abordará el Tribunal Especial para la Paz, por ello se hace necesario analizar y evaluar la posición que ha asumido la ECHR en este tipo de situaciones vulneradoras de derechos humanos, para recopilar y unificar la visión internacional que existe sobre este delito y de esta manera facilitar futuros abordajes al respecto. Este estudio es necesario, por cuanto la doctrina que aborda la posición de la ECHR frente a los casos de desaparición forzada de personas no lo hace de una forma específica y exhaustiva, en especial, en todo lo relacionado con la evolución jurisprudencial de este Alto Tribunal y el análisis total de las sentencias relacionadas con el tema.

Las investigaciones que se han desarrollado sobre los casos de desaparición forzada en Europa, por autores como Chinchon, Dijkstra y otros, se apoyan, principalmente, en aquellos fallos que han resultado coyunturales para la Corte, como lo son el de Varnava, Chipre o Janowiec (Chinchon Álvarez, 2015) (Dijkstra , Klann , Ruimschotel, \& Wijnkoop, 2002) (Kyriakou, 2012), también se destacan los estudios comparativos sobre el material probatorio que utilizó la Corte en los casos de desaparición forzada (Claude, 2010), o los abordajes que tenían en cuenta el contexto histórico (Erener, 2015) (Finucane, 2011); sin embargo, consideramos que estos aportes investigativos han estudiado de manera incompleta la totalidad de sentencias que ha emitido el Alto Tribunal en los casos de desaparición forzada.

El artículo aborda dos aspectos a considerar; el primero corresponde a la evolución jurisprudencial de la ECHR en los casos de desaparición forzada y en donde se analiza los siguientes aspectos: a) los derechos vulnerados, b) la declaración de responsabilidad del Estado, c) los instrumentos internacionales aplicados y d) la definición de desaparición forzada adoptada por la Corte; el segundo expone el análisis de factores importantes que rodearon las desapariciones, haciendo énfasis en: a) el contexto de las desapariciones, b) la participación del Estado en los hechos, c) la normatividad interna de los Estados demandados y d) la respuesta del Estado demandado ante el conocimiento de la desaparición. 


\section{Metodología}

En primer lugar, se realizó una búsqueda e identificación de las sentencias de la Corte Europea de Derechos Humanos que versaban sobre desaparición forzada a través del buscador Human Rights Documentation (HUDOC) de la ECHR, la selección y posterior análisis documental del material recolectado se efectuó usando un método de observación y revisión hermenéutico de orden cualitativo, donde se tomó cada una de las sentencias para hacer un ejercicio de análisis comparativo entre estas, con el fin de determinar las semejanzas y diferencias entre los contextos, la responsabilidad estatal, los instrumentos internacionales utilizados, la posición de la Corte frente al concepto de desaparición forzada y la interpretación que ha hecho este organismo frente a los derechos vulnerados de la Convención Europea de Derechos Humanos.

\section{Evolución jurisprudencial de la ECHR}

A continuación se desarrollan los aspectos más destacables del análisis comparativo que se hizo a las 24 sentencias de la ECHR.

\section{Violación de derechos humanos en los casos de desaparición forzada}

Del análisis hecho, se puede observar que la ECHR ha abordado el derecho a la vida partiendo siempre de tres pilares fundamentales: a. la muerte comprobada de las víctimas, b. la presunción de muerte por el tiempo transcurrido desde la desaparición, c. la vulneración al derecho por incumplir las obligaciones de investigación. La Tabla 1 muestra el número de sentencias en las que se ha declarado violado el derecho a la vida.

En este sentido, para la Corte el reconocimiento de responsabilidad por muerte comprobada de una persona o la presunción de este hecho dependía en principio de la evaluación que podía hacer el alto Tribunal sobre el material probatorio disponible para llegar a dichas conclusiones (Kurt vs. Turquía, 1998); sin embargo, este abordaje se ha vuelto más amplio con los años, lo que permite declarar la responsabilidad del Estado en virtud a conjeturas relacionadas con el paso del tiempo, los resultados forenses vinculantes, las declaraciones de testigos, la actitud de las autoridades, la responsabilidad en el manejo de sus registros, los elementos circunstanciales o la colaboración prestada para con las víctimas o con la ECHR (Çakici vs. Turquia, 1999) (Timurtas vs. Turquía, 2000) (Akhmadova y Sadulayeva vs. Rusia, 2007) (Imakayeva vs. Rusia, 2007).

Así mismo, la violación al derecho a la vida en los casos de desaparición forzada se puede dar en aquellas situaciones en las que el Estado era conocedor o consciente de 
un riesgo latente sobre la persona desaparecida y aun así no moviliza a las autoridades para prevenir la consumación de un delito (Gongadze vs. Ucrania, 2006). También cuando el Estado no llama a rendir cuentas a sus agentes de forma oportuna, no abre las investigaciones judiciales diligentemente o adopta disposiciones de derecho interno encaminadas a prevenir la consumación de este tipo de delitos o sancionarlos adecuadamente (Orhan Vs Turquía, 2002) ( Khadzhialiyev y otros vs. Rusia, 2009).

Por otro lado, la Corte ha entendido que las violaciones al derecho a la vida se dan cuando existen pruebas de un uso injustificado de la fuerza por parte de las autoridades (Orhan vs. Turquia, 2002), circunstancia que en situaciones graves de conflictos armados ha llevado a la Corte a interpretar la violación del derecho a la vida desde las normas del Derecho Internacional Humanitario (Varnava vs. Turquia, 2009).

En relación con la prohibición de tortura, la ECHR siempre se ha visto obligada a diferenciar dos tipos de víctimas, por un lado, a los desaparecidos y por otro, a sus familiares y seres queridos. Los fallos que declaran la responsabilidad por vulneración a este artículo del Convenio se pueden observar en la Tabla 1.

En el caso de los desaparecidos, es claro para la Corte que los tratos crueles solamente se configuran cuando existen elementos probatorios determinantes que permiten corroborar la existencia de dicha conducta (Yusupova y Zaurbekov vs. Rusia, 2004). La contravención a la prohibición de tortura se puede dar también por las omisiones al deber de proteger las personas de los tratos crueles y torturas (Mahmut Kaya vs. Turquía, 2000). Del mismo modo, la Corte ha ido adoptando, paulatinamente, una posición apoyada en presunciones y pruebas orientadas a declarar la responsabilidad por torturas y malos tratos en circunstancias, que dada la naturaleza y características de la detención, involucran maltrato en un marco mental, espiritual e incluso sexual del desaparecido (El-Masri vs. The Former Yugoslav Republic of Macedonia, 2012).

Inclusive, para que los familiares de un desaparecido puedan ser considerados como víctimas de tortura, tratos crueles o inhumanos, se tomaron en cuenta factores relevantes como la proximidad del nexo familiar, la angustia, la participación en los intentos por buscar información de la víctima y sobre todo, la respuesta por parte de las autoridades en los intentos de los familiares por conocer el paradero del desaparecido (Akdeniz vs. Turquía, 2001) (Janowiec and others vs. Rusia, 2013).

La violación del derecho a la libertad está ligada, principalmente, a la privación de la libertad de forma arbitraria por agentes estatales, no obstante, esto no ha sido corroborado y sancionado por parte del alto Tribunal en todos los casos, debido a la ausencia de material probatorio determinante. En cualquier caso, para la Corte, toda privación de la libertad siempre debe ir acompañada de una inmediata 
atención judicial que evite la consumación de otras violaciones a los derechos humanos y que eviten poner en peligro a la persona retenida, comprometiendo así los deberes que tiene el Estado para con los ciudadanos. Ningún tipo de circunstancia extraordinaria que altere el orden público o la seguridad nacional exime a los Estados de cumplir estos deberes asociados a las garantías judiciales que deben acompañar, en todo momento, el derecho a la libertad (Tanis y otros vs. Turquía, 2005) (El-Masri vs. The Former Yugoslav Republic of Macedonia, 2012).

De tal manera que, después de una detención las autoridades tienen el deber de proteger y justificar el paradero de la víctima. Una detención no reconocida se hace evidente cuando las pruebas testimoniales y circunstanciales están acompañadas de inexactitud o ausencia de registros y una negativa para dar cuenta sobre los mismos. En todos estos aspectos, el Estado es plenamente responsable no solo por la detención, sino también por todos los actos delictivos presumibles o comprobables en perjuicio del desaparecido (Çakici vs. Turquía, 1999).

La interpretación que hace la Corte respecto al derecho a la libertad configurada en el convenio, siempre ha sido el elemento que acompaña de forma más cercana la aproximación al concepto de desaparición forzada, ya que es allí donde el tribunal trata de configurar o describir las características y elementos del delito desde una perspectiva internacional.

En algunos casos la Corte falla respecto al derecho a la vida privada y familiar, debido a que los casos van acompañados de situaciones donde se destruyen pueblos, casas o propiedad privada (Orhan vs. Turquía, 2002). Además, la violación a este artículo se puede dar cuando agentes del Estado adoptan medidas de búsqueda o decomiso de pertenencia sin la autorización o salvaguardas necesarias (Imakayeva vs. Rusia, 2007). Por otro lado, y de mayor importancia, la vulneración ha configurado cuando la Corte establece que la vida privada es un concepto amplio, sujeto a la integridad física y moral de una persona, donde las relaciones sociales con otros individuos, la familia y el mundo que le rodea son elementos que se ven seriamente afectados con la privación de la libertad física en los casos de desaparición forzada (El-Masri vs. The Former Yugoslav Republic of Macedonia, 2012)

La vulneración del derecho a un recurso efectivo se desarrolla, toda vez que el Estado no adopta mecanismos jurisdiccionales apropiados para atender una denuncia de desaparición y reparar a las víctimas, dicha reparación debe ser efectiva en la práctica y en la ley, sin obstáculos injustificados por actos u omisiones de las autoridades. Además, no se suple únicamente con el pago de una indemnización, también implica la apertura de una investigación exhaustiva y efectiva en los casos en que se hayan cometido violaciones graves contra el derecho a la vida, la 
integridad y la prohibición de tortura u otros que resulten fundamentales para el ser humano. Estas investigaciones deben conducir a la identificación y sanción de los perpetradores y debe asegurar la participación de las víctimas y sus familiares de forma activa (Kurt vs, Turquía, 1998) (Akhmadova y Sadulayeva vs. Rusia, 2007).

En relación con el derecho de no discriminación se evidencia que la Corte no ha encontrado nunca material probatorio suficiente, ni ha llegado a la conclusión de la existencia de situaciones que configuren una discriminación negativa contra la población por motivo de su origen étnico, ello pese a que los casos de desaparición forzada se presentan, en general, contra las minorías étnicas (Ipek vs. Turquía, 2004).

Para la Corte, se ve vulnerado el artículo 34 del Convenio Europeo de Derechos Humanos sobre demandas individuales en los casos de desaparición forzada, cuando el Estado o alguno de sus órganos o agentes presionan a los individuos de algún modo para que retiren o modifiquen sus quejas ante el Sistema Europeo de Derechos Humanos. En este contexto, "la presión incluye no solo la coacción directa y actos flagrantes de intimidación, sino también otros actos o contactos indirectos inadecuados diseñados para disuadir o desalentar a los solicitantes de instaurar una petición en virtud de la Convención" (Salman vs. Turquía, 2000).

De manera particular, en las situaciones que han involucrado conflictos armados de importancia para el contexto europeo, cualquier infracción a los derechos humanos que se salga del marco de competencia temporal de la Corte, por presentar hechos anteriores a la ratificación del convenio, estarán sujetos a que se presenten vulneraciones continuas de derechos humanos que no hayan cesado con el paso del tiempo y en donde el Estado se ha mostrado negligente u omisivo para reivindicar y reparar los derechos de las víctimas (Antonio Gutierrez Dorado y Carmen Dorado vs. España, 2012).

La Tabla 1 muestra el comparativo entre los artículos del Convenio Europeo de Derechos Humanos y el número de sentencias de la ECHR, sistematizadas por país, en las cuales se ha declarado violado el derecho en cuestión. 
Tabla 1

Relación entre los artículos del Convenio y los fallos judiciales de la ECHR

\begin{tabular}{|c|c|}
\hline $\begin{array}{c}\text { Artículo del Convenio Europeo de } \\
\text { Derechos Humanos }\end{array}$ & $\begin{array}{c}\text { Número de sentencias en las que se } \\
\text { declaran violados los derechos }\end{array}$ \\
\hline Artículo 2 derecho a la vida & $\begin{array}{l}12 \text { sentencias contra Turquía } \\
7 \text { sentencias contra Rusia } \\
1 \text { sentencia contra Ucrania }\end{array}$ \\
\hline Artículo 3 prohibición de la tortura & $\begin{array}{l}10 \text { sentencias contra Turquía } \\
7 \text { sentencias contra Rusia } \\
1 \text { sentencia contra Ucrania } \\
1 \text { sentencia contra Macedonia }\end{array}$ \\
\hline $\begin{array}{l}\text { Artículo } 5 \text { derecho a la libertad y la } \\
\text { seguridad }\end{array}$ & $\begin{array}{l}8 \text { sentencias contra Turquía } \\
7 \text { sentencias contra Rusia } \\
1 \text { sentencia contra Macedonia }\end{array}$ \\
\hline $\begin{array}{l}\text { Artículo } 8 \text { derecho al respeto de la vida } \\
\text { privada y familiar }\end{array}$ & $\begin{array}{l}1 \text { sentencia contra Rusia } \\
1 \text { sentencia contra Macedonia }\end{array}$ \\
\hline Artículo 13 derecho a un recurso efectivo & $\begin{array}{l}10 \text { sentencias contra Turquía } \\
7 \text { sentencias contra Rusia } \\
1 \text { sentencia contra Ucrania } \\
1 \text { sentencia contra Macedonia }\end{array}$ \\
\hline $\begin{array}{l}\text { Artículo } 34 \text { (anterior artículo 25) } \\
\text { demandas individuales }\end{array}$ & 4 sentencias contra Turquía \\
\hline
\end{tabular}

Fuente: Elaboración propia

\section{Análisis de la declaración de la Corte sobre responsabilidad del Estado}

El análisis de las sentencias sugiere que este alto Tribunal suele declarar siempre la responsabilidad del Estado por las vulneraciones cometidas a los derechos humanos en los casos de desaparición de personas, las únicas excepciones se encuentran en aquellas sentencias donde por factores de admisibilidad, competencia o por ausencia de elementos probatorios, el tribunal no conoció ni declaró la responsabilidad internacional. Se puede evidenciar también, que la gran mayoría de los casos presentan una declaración de responsabilidad directa por las desapariciones, aunque la responsabilidad es variable en relación con las omisiones judiciales y estatales tal como lo evidencia la Tabla 2.

A continuación, se hará un análisis de los casos más sobresalientes al respecto:

En 12 de los 13 casos analizados contra la república de Turquía (ver Tabla 2), la Corte declara responsable al Estado por las desapariciones directas de las personas. Ello quiere decir, que fue plenamente demostrada la participación de agentes estatales en la comisión de los hechos. En efecto, en los casos cuyos sucesos corresponden 
a situaciones contemporáneas, la Corte siempre manifestó la responsabilidad del Estado por las omisiones de los agentes estatales en las investigaciones judiciales.

El caso Gongagze se destaca debido a que configura un ejemplo de la responsabilidad en la que incurre un Estado en casos de desaparición de personas cuando se presenta un factor de gravedad como es el que la víctima hubiese recibido amenazas, se hubiesen presentado denuncias ante las autoridades públicas y ante lo cual, no recibiera apoyo para salvaguardar la vida e integridad propias. Esta es una evidencia clara de las graves omisiones en las que incurre un estado y deberían ser tomadas como presunciones graves que pueden apuntar a grados de responsabilidad mucho más amplios (Gongadze vs. Ucrania, 2006).

El caso El Masri contra la República de Macedonia es una de las muchas evidencias en el contexto moderno, que presenta la responsabilidad por violación a los derechos humanos, no solo como un deber que se exige al Estado protagonista de los hechos, ya sea porque la persona residía allí o era nacional del país, sino también hacia otros Estados involucrados por medio de sus fuerzas de inteligencia internacional, fuerzas armadas en misión extranjera o incluso a aquellos que permiten se cometan este tipo de violaciones en situaciones, que incluyen conflictos de carácter internacional, dentro de los límites jurisdiccionales del territorio sobre el cual ejercen soberanía.

\section{Tabla 2}

Relación entre el tipo de responsabilidad del Estado y las sentencias

\begin{tabular}{|l|l|}
\hline \multicolumn{1}{|c|}{ Responsabilidad del Estado } & \multicolumn{1}{|c|}{$\begin{array}{c}\text { Número de sentencias en las que se } \\
\text { declara la responsabilidad }\end{array}$} \\
\hline $\begin{array}{l}\text { Responsabilidad directa por las } \\
\text { desapariciones }\end{array}$ & 1 sentencia contra Turquía \\
\hline $\begin{array}{l}\text { Responsabilidad directa por las } \\
\text { desapariciones y por las omisiones } \\
\text { judiciales }\end{array}$ & $\begin{array}{l}11 \text { sentencias contra Turquía } \\
3 \text { sentencias contra Rusia } \\
1 \text { sentencia contra Macedonia }\end{array}$ \\
\hline $\begin{array}{l}\text { Responsabilidad únicamente por las } \\
\text { omisiones judiciales }\end{array}$ & $\begin{array}{l}1 \text { sentencia contra Turquía } \\
4 \text { sentencias contra Rusia } \\
1 \text { sentencia contra Ucrania }\end{array}$ \\
\hline Sin declaración de responsabilidad & 1 sentencia contra Rusia \\
& 1 sentencia contra España \\
\hline
\end{tabular}

Fuente: Elaboración propia 


\section{Instrumentos internacionales aplicados}

En términos generales, el principal instrumento internacional aplicado por la ECHR es la Convención Europea de Derechos Humanos, su interpretación, eventualmente, está acompañada de los protocolos adicionales propios del sistema europeo; en los casos de desaparición de personas se evidencia, principalmente, el uso del protocolo 1 de la Convención tal como se manifiesta en las sentencias. Es decir, se aprecia en gran medida el valor del material jurisprudencial propio de la Corte, como un instrumento internacional de importancia.

Es únicamente en los casos más relevantes, por el contexto histórico, por la gravedad de los hechos, por el auge mediático, entre otras razones, donde la Corte acude a instrumentos internacionales provenientes de otros sistemas jurisdiccionales como la Corte Interamericana o del ámbito internacional, con influencia global como la ONU o el Concejo de Europa, para afianzar la interpretación en su jurisprudencia.

A continuación se presenta la lista de los principales instrumentos internacionales que ha usado la ECHR en los casos de desaparición forzada:

- $\quad$ Convenios de Ginebra (1949)

- Declaración de las Naciones Unidas para la protección de personas desaparecidas (1992)

- Declaración sobre la protección de todas las personas contra las desapariciones forzadas (1992)

- $\quad$ Pacto Internacional de Derechos Civiles y Políticos (1966)

- Convenios de Viena (1969)

- Convención Interamericana Sobre Desaparición Forzada de Personas (1994)

- Sentencias de la Corte Interamericana de Derechos Humanos donde se tratan situaciones de desaparición forzada de personas

- $\quad$ Resoluciones del Comité de Derechos Humanos de la ONU en materia de desaparición forzada

- $\quad$ Reportes de Amnistía Internacional y otros organismos especializados en la defensa de Derechos Humanos

- $\quad$ Reportes y resoluciones del Comité Europeo de Prevención contra la Tortura

- $\quad$ Resoluciones del Comité Europeo para la Prevención de la Tortura

- Jurisprudencia de la ECHR

De manera particular se destacan los siguientes casos por el notorio uso de instrumentos internacionales: 
Kurt (1998), uno de los primeros y más notorios casos de desaparición de personas en Turquía, donde la Corte interpreta convenios de la ONU y del Sistema Interamericano sobre desaparición forzada de personas.

Salman (2000), caso de importancia, ya que los hechos y las pruebas obligaron al Tribunal Europeo a revisar instrumentos internacionales relacionados con los malos tratos y la prohibición de tortura.

Varnava (2009), uno de los más completos casos de desaparición de personas en Turquía. Su Jurisprudencia se utiliza con frecuencia en otros de la Corte, para analizar situaciones de desapariciones similares. Aquí la Corte tuvo que acudir a informes del comité de personas desaparecidas de la ONU, en especial, al reporte generado con posterioridad a la operación Atila en 1974 por la ONU y el Concejo de Europa. También se recurrió a informes del grupo de trabajo de la ONU sobre personas desaparecidas involuntaria o forzosamente.

Janowiec (2009), es uno de los más sobresalientes casos en Rusia debido al contexto histórico en el que se genera y a la gravedad de los hechos, en la Segunda Guerra Mundial. Para poder abordar este incidente la ECHR tuvo que acudir al convenio de la Haya de 1907 sobre prisioneros de guerra, al convenio de Ginebra de 1929, a la carta estatutaria del tribunal de Nuremberg, la Convención de Viena sobre derecho de los tratados y a la Convención sobre la imprescriptibilidad de los crímenes de guerra y de los crímenes de lesa humanidad.

El Masri (2012), este caso en particular ha llamado la atención de diferentes organizaciones internacionales que se dedican a la defensa de los Derechos Humanos, también generó el interés de diversos medios de comunicación, al punto que el Concejo de Europa tuvo que manifestarse. Para abordar este acontecimiento se tuvo que acudir a resoluciones del Parlamento y del Concejo de Europa, resoluciones del concejo de seguridad de la ONU, resoluciones del Comité de Derechos Humanos de la ONU, resoluciones del gobierno alemán, convenio de Viena sobre relaciones consulares, manual de investigación y documentación de la ONU, cuando se presentan casos de tortura y malos tratos, la comisión de derecho internacional sobre la responsabilidad de los actos ilegales del Estado, casos de las altas Cortes de Inglaterra, Suecia y Estados Unidos.

\section{Definición del concepto de desaparición forzada de personas}

Del estudio realizado, se evidencia que en términos generales la Corte no ha establecido entre sus estatutos, sus protocolos adicionales o por medio de resoluciones del Concejo de Europa, ninguna definición exacta de lo que es para este sistema 
una desaparición forzada. Tanto el Sistema Europeo como la jurisprudencia de la Corte no diferencian claramente entre una desaparición normal (propiciada por actos criminales comunes) y una desaparición forzada.

Son específicos los casos Varnava, Kurt y El Masri, en los que la Corte tiene que traer a colación convenios internacionales de la Corte Interamericana de Derechos Humanos o de la ONU para interpretar el significado de lo que es una desaparición forzada de personas. En este sentido, se puede inferir que para la Corte la definición de desaparición forzada de personas es la manifestada en instrumentos como la Convención Interamericana Sobre Desaparición Forzada de Personas:

Artículo 2. Para los efectos de la presente Convención, se considera desaparición forzada la privación de la libertad a una o más personas, cualquiera que fuere su forma, cometida por agentes del Estado o por personas o grupos de personas que actúen con la autorización, el apoyo o la aquiescencia del Estado, seguida de la falta de información o de la negativa a reconocer dicha privación de libertad o de informar sobre el paradero de la persona, con lo cual se impide el ejercicio de los recursos legales y de las garantías procesales pertinentes. (Organizacion de los Estados Americanos, 1994)

Y del mismo modo, la definición expuesta en el artículo 1, de la Declaración sobre la protección de todas las personas contra las desapariciones forzadas:

Artículo 1. 1. Todo acto de desaparición forzada constituye un ultraje a la dignidad humana. Es condenado como una negación de los objetivos de la Carta de las Naciones Unidas y como una violación grave manifiesta de los derechos humanos y de las libertades fundamentales proclamados en la Declaración Universal de Derechos Humanos y reafirmados y desarrollados en otros instrumentos internacionales pertinentes. 2. Todo acto de desaparición forzada sustrae a la víctima de la protección de la ley y le causa graves sufrimientos, lo mismo que a su familia. Constituye una violación de las normas del derecho internacional que garantizan a todo ser humano, entre otras cosas, el derecho al reconocimiento de su personalidad jurídica, el derecho a la libertad y a la seguridad de su persona y el derecho a no ser sometido a torturas ni a otras penas o tratos crueles, inhumanos o degradantes. Viola además el derecho a la vida, o lo pone gravemente en peligro. (Asamblea General de la Organización de las Naciones Unidas, 1992)

Sin embargo, la ECHR también ha aplicado el concepto de desaparición forzada o involuntaria de personas de forma autónoma en algunos de sus fallos, y ha establecido algunos de los elementos o circunstancias que configurarían una desaparición, esto ha sido desarrollado de forma implícita cuando el Tribunal interpreta 
las violaciones a los derechos del Convenio Europeo de Derechos Humanos. En la Tabla 3 se observa la relación antes descrita, la cual es ampliada en los ejemplos de los casos judiciales mencionados a continuación:

Las circunstancias que rodean una desaparición donde intervienen agentes estatales estará comprobada siempre que se demuestre una detención auténtica y motivada por parte de las autoridades, ausencia de explicaciones sobre el paradero del detenido, falta de justificación sobre la necesidad del uso de la fuerza estatal en su contra y finalmente, la existencia de un contexto de fomento a la falta de rendición de cuentas por parte de las autoridades (Timurtas vs. Turquía, 2000) ( Khadzhialiyev y otros vs. Rusia, 2009).

La Corte ha considerado que el secuestro y la detención del demandante son actos que encajaban dentro de la definición de "desaparición forzada" acorde a las fuentes del Derecho Internacional, y aunque este fenómeno sea temporal, si se caracteriza por una situación continua de incertidumbre, falta de explicaciones, que se extienda el cautiverio por un periodo de tiempo considerable, se considera comprobada dicha desaparición (El-Masri vs. The Former Yugoslav Republic of Macedonia, 2012).

Tabla 3

Definición de desaparición forzada usada por la ECDH

\begin{tabular}{|l|l|}
\hline \multicolumn{1}{|c|}{$\begin{array}{c}\text { Definición de desaparición forzada } \\
\text { utilizada por la Corte }\end{array}$} & \multicolumn{1}{c|}{ Número de sentencias } \\
\hline Sin definición & $\begin{array}{l}7 \text { sentencias contra Turquía } \\
6 \text { sentencias contra Rusia } \\
1 \text { sentencia contra España }\end{array}$ \\
\hline $\begin{array}{l}\text { Sin definición exacta pero con abordaje } \\
\text { implícito }\end{array}$ & $\begin{array}{l}3 \text { sentencias contra Turquía } \\
2 \text { sentencias contra Rusia }\end{array}$ \\
\hline $\begin{array}{l}\text { Sin definición exacta pero con abordaje } \\
\text { orientado a desaparición criminal común }\end{array}$ & $\begin{array}{l}1 \text { sentencia contra Turquía } \\
1 \text { sentencia contra Rusia } \\
1 \text { sentencia contra Ucrania }\end{array}$ \\
\hline $\begin{array}{l}\text { Sin definición exacta pero con abordaje } \\
\text { derivado de instrumentos internacionales } \\
\text { (ONU y Sistema Interamericano) }\end{array}$ & $\begin{array}{l}2 \text { sentencias contra Turquía } \\
1 \text { sentencia contra Macedonia }\end{array}$ \\
\hline
\end{tabular}

Fuente: Elaboración propia

\section{Análisis de los factores de importancia en las desapariciones}

A continuación se aborda el análisis de los diferentes indicadores relacionados con factores circunstanciales, espaciales, temporales o normativos que resultan de importancia en los diferentes casos de desaparición forzada. 


\section{Contexto de las desapariciones}

Del análisis hecho a las sentencias se puede deducir que las desapariciones forzadas en Europa están determinadas, principalmente, por un contexto de conflictos armados, guerras, operaciones militares contra grupos insurgentes, terroristas o separatistas; la única excepción se ha encontrado en el caso de Gongadze contra la República de Ucrania (ver Tabla 4). De manera análoga, los factores históricos, geográficos y excepcionalmente circunstanciales permiten inferir que en Europa se están presentando situaciones de desaparición de personas que involucran a países ajenos al territorio nacional, como en el caso de El-Masri contra la República de Macedonia o el de Varnava contra la República de Turquía, u organizaciones relevantes de la comunidad internacional como el Consejo de Europa o la ONU.

Respecto a la mayoría de los casos contra la república de Turquía, es particularmente importante el contexto geopolítico en el que se mueve el sur oriente del país, ello por cuanto sus habitantes están inmersos en una lucha, desde hace varias décadas, por culminar un proceso de emancipación y reconocimiento de Kurdistán como país soberano; en este sentido, los ataques, la comisión de graves violaciones a los derechos humanos y delitos de lesa humanidad contra la población turca abarcan no solo a la región Kurda de Turquía, sino también a las tribus kurdas del norte de Irán, Irak y Siria que se han visto envueltos, en este y otros conflictos asociados, por la distribución del grupo insurgente Partido de los Trabajadores Kurdos (PKK) a estos países. El conflicto Kurdo de Turquía ha dejado a la fecha un margen de más de doscientos mil desaparecidos (Zorrilla, 2014).

En este sentido, se destaca el caso de Timurtas contra la república de Turquía, donde el contexto de la desaparición incluye la privación temporal de la libertad de un ciudadano Sirio junto al señor Timurtas. Esta persona resulta ser un testigo clave para dar fe de los hechos y confirmarle a la ECHR la presencia física del señor Timurtas bajo la responsabilidad de militares turcos (Timurtas vs. Turquía, 2000).

Respecto a la mayoría de los casos contra la república de Rusia, es importante mencionar que en la región de Chechenia se ha desarrollado el conflicto de más larga duración en la Europa contemporánea y que ha dejado como resultado alrededor de 100000 personas muertas o desaparecidas; el contexto de este conflicto desde su inicio en la década de 1990 ha llamado la atención de toda la comunidad internacional, principalmente del Concejo de Europa, con el ánimo de evitar que se sigan cometiendo graves violaciones a los derechos humanos de la comunidad chechena y se llegue a un acuerdo de paz (Chelysheva, 2006). 
En la extensión internacional de las sentencias dirigidas contra la república de Rusia se destaca el caso de Imakayeva, donde por la gravedad de los hechos y los ataques, persecución moral y amenazas en contra de la demandante para proteger su vida, le llevaron a solicitar asilo en otros países (Imakayeva vs. Rusia, 2007).

En el caso El Masri contra la república de Macedonia, se destaca una preocupante situación, ya que es la primera desaparición de personas en la que se evidencia que la comisión de este delito trasciende los límites jurisdiccionales y territoriales de un país, ya que esta se desarrolló mediante una operación coordinada con agentes estatales de Estados Unidos, quienes llevaron al señor Masri, en contra de su voluntad, a Afganistán, y allí fue sometido a torturas e interrogatorios, procedimientos fuera del ordenamiento jurídico de alguno de estos países. (El Masri vs. The Former Yugoslav Republic of Macedonia, 2012). Al respecto, organizaciones especializadas en la defensa de los derechos humanos han investigado y han concluido que:

El gobierno de Estados Unidos ha creado un sistema de detenciones de amplio alcance para sospechosos de terrorismo y otras personas que considera implicadas en la "guerra contra el terror". Forman parte de este sistema los traslados ilegales de presuntos terroristas (entregas), la reclusión en centros de detención, tanto reconocidos como secretos, controlados por Estados Unidos y situados en territorio no estadounidense, y la reclusión a instancias de Estados Unidos en centros controlados por otros gobiernos (detención por encargo). Todos estos elementos se caracterizan por la ausencia de salvaguardias procesales y de protección de derechos fundamentales (por ejemplo, detención sin cargos y sin posibilidad de revisión) e infringen el derecho internacional. En muchos casos, las personas detenidas por Estados Unidos o por sus aliados son trasladadas ilegalmente varias veces y es posible que hayan estado recluidas en secreto en diferentes lugares. (Amnistia Internacional, CAGEPRISIONERS, Human Rights Watch, Center For Constitutional Rights, Reprieve, CHR \& GJ, 2007, pág. 4)

Tres de las sentencias analizadas (Chipre vs. Turquía, Varnava vs. Turquía, Janowiec vs. Rusia) presentan situaciones relacionadas con conflictos militares entre dos países (la operación Atila en el conflicto entre Turquía y Chipre y la invasión rusa a Polonia durante la Segunda Guerra Mundial), que generaron como consecuencia la desaparición de personas. La operación Atila en el conflicto entre Turquía y Chipre y la invasión rusa a Polonia durante la Segunda Guerra Mundial, involucraron la participación de la comunidad internacional, por un lado, por la gravedad y el alcance de los mismos, pero sobre todo, por cuanto estos casos pertenecían a un contexto histórico anterior a la ratificación de los convenios europeos en materia de derechos humanos. 
En este sentido, se destaca el caso de Chipre contra Turquía, ya que es uno de los pocos dentro de los sistemas regionales de derechos humanos donde un Estado interpone la demanda contra otro. En el caso particular, las desapariciones forzadas evidencian que las violaciones a los derechos humanos son fenómenos que están trascendiendo los límites jurídicos de un solo país y empieza a involucrar a la comunidad internacional. En este caso, específico, Chipre demandó diversas violaciones a los derechos humanos, pero una de las que revestía mayor gravedad por su carácter continuo, era la desaparición de 1485 chipriotas durante la operación Atila (1974).

En la jurisprudencia analizada, 4 de los casos (Chipre vs. Turquía, Varnava vs. Turquía, Janowiec vs. Rusia y Gutiérrez Dorado vs. España) corresponden a situaciones donde las desapariciones datan de periodos históricos con bastante antigüedad. Estos casos fueron abordados por la Corte Europea recientemente, pese a que las situaciones y contextos que dieron origen a las desapariciones sucedieron con anterioridad a la ratificación del Convenio Europeo de Derechos Humanos o sus protocolos adicionales o a la jurisdicción de la ECHR. En cada uno de los tres casos la Corte debió entrar a analizar si era competente para definir el debate jurídico generado y responsabilizar al Estado. 
Tabla 4

Relación entre los conflictos europeos y los casos de desaparición forzada

\begin{tabular}{|c|c|}
\hline Conflicto & Sentencias \\
\hline $\begin{array}{l}\text { Conflicto militar contra el grupo insurgente } \\
\text { PKK (Partido Laborista Kurdo) en la región } \\
\text { de Kurdistán al sudeste de Turquía }\end{array}$ & $\begin{array}{l}\text { Kurt vs. Turquía(1998) } \\
\text { Cakici vs. Turquía(1999) } \\
\text { Ertak vs. Turquía (2000) } \\
\text { Mahmut Kaya vs. Turquía (2000) } \\
\text { Salman vs. Turquía (2000) } \\
\text { Timurtas vs. Turquía (2000) } \\
\text { Akdeniz vs. Turquía (2001) } \\
\text { Avsar vs. Turquía (2002) } \\
\text { Orhan vs. Turquía (2002) } \\
\text { Ipek vs. Turquía (2004) } \\
\text { Tanis vs. Turquía (2005) } \\
\end{array}$ \\
\hline Operación militar Atila en la isla de Chipre & \begin{tabular}{|l|} 
Chipre vs. Turquía (2001) \\
Varnava vs. Turquía (2009) \\
\end{tabular} \\
\hline Conflicto Checheno & $\begin{array}{l}\text { Akhmadova y Sadulayeva vs. Rusia (2007) } \\
\text { Imakayeva vs. Rusia (2007) } \\
\text { Yusupova y Zaurbekov (2008) } \\
\text { Magomed Musayev y otros vs. Rusia (2009) } \\
\text { Malsagova y otros vs. Rusia (2009) } \\
\text { Kadzhialiev vs. Rusia (2009) } \\
\text { Sadulayeva vs. Rusia (2010) }\end{array}$ \\
\hline $\begin{array}{l}\text { Invasión de tropas rusas a Polonia durante } \\
\text { la Segunda Guerra Mundial }\end{array}$ & Janowiec vs. Rusia (2013) \\
\hline $\begin{array}{l}\text { Ataques contra periodistas que criticaban a } \\
\text { altos funcionarios del gobierno ucraniano }\end{array}$ & Gongadze vs. Ucrania (2006) \\
\hline Guerra civil española & Gutiérrez Dorado vs. España (2012) \\
\hline $\begin{array}{l}\text { Conflicto y guerra contra el terrorismo en } \\
\text { medio oriente }\end{array}$ & El Masri vs. Macedonia (2012) \\
\hline
\end{tabular}

Fuente: Elaboración propia

\section{Participación de los estados demandados en los hechos}

La mayoría de las desapariciones se dan en contextos donde miembros de las fuerzas públicas (ejército o policía) están involucrados de forma circunstancial o directa en la privación de la libertad a personas. Se puede inferir, además, que las desapariciones fueron cometidas por personas con dominio o acceso al monopolio de las armas en sus respectivos países de origen y con ostentación de un grado superior de autoridad o dominancia sobre las víctimas. Para hacer este análisis no se tomó en cuenta la versión del Estado, debido a que este siempre niega los hechos o se limita a defenderse en los casos analizados. La relación estudiada de la participación del Estado y las sentencias se puede observar en la Tabla 5. 
Se destacan los casos de Tanis contra Turquía, Mahmut Kaya contra Turquía, Kadzhialyev contra Rusia, Malsagova y otros contra Rusia, Yusupova y Zaurbekov contra Rusia, ya que los hechos del caso no demuestran con claridad la pertenencia o no a las fuerzas públicas de los hombres vestidos y armados como militares que llegaron para retener y privar de la libertad a las víctimas ( (Mahmut Kaya vs. Turquía, 2000) (Yusupova y Zaurbekov vs. Rusia, 2004) (Tanis y otros vs. Turquía, 2005) (Khadzhialiyev y otros vs. Rusia, 2009) (Sadulayeva vs. Rusia, 2010). Conforme a lo anterior, resulta importante mencionar que en el caso de Akhmadova y Saludayeva contra Rusia, es claro para las víctimas que la desaparición fue cometida por agentes paramilitares al servicio del Estado (Akhmadova y Sadulayeva vs. Rusia, 2007).

\section{Tabla 5}

Relación la participación del Estado en los hechos y los fallos judiciales

\begin{tabular}{|c|c|}
\hline $\begin{array}{c}\text { PARTICIPACIÓN DEL ESTADO EN } \\
\text { LOS HECHOS } \\
\text { (Versión de los peticionarios) }\end{array}$ & SENTENCIAS \\
\hline Si hubo participación & $\begin{array}{l}\text { Kurt vs. Turquía (1998) } \\
\text { Cakici vs. Turquía (1999) } \\
\text { Ertak vs. Turquía (2000) } \\
\text { Salman vs. Turquía (2000) } \\
\text { Timurtas vs. Turquía (2000) } \\
\text { Akdeniz vs. Turquía (2001) } \\
\text { Chipre vs. Turquía (2001) } \\
\text { Avsar vs. Turquía (2002) } \\
\text { Orhan vs. Turquía (2002) } \\
\text { Ipek vs. Turquía (2004) } \\
\text { Tanis vs. Turquía (2005) } \\
\text { Varnava vs. Turquía (2009) } \\
\text { Imakayeva vs. Rusia (2007) } \\
\text { Magomed Musayev y otros vs. Rusia (2009) } \\
\text { Kadzhialiev vs. Rusia (2009) } \\
\text { Sadulayeva vs. Rusia (2010) } \\
\text { Janowiec vs. Rusia (2013) } \\
\text { Gongadze vs. Ucrania (2006) } \\
\text { Gutierrez Dorado vs. España (2012) } \\
\text { El Masri vs. Macedonia (2012) }\end{array}$ \\
\hline Participación no demostrable & $\begin{array}{l}\text { Mahmut Kaya vs. Turquía (2000) } \\
\text { Yusupova y Zaurbekov (2008) } \\
\text { Malsagova y otros vs. Rusia (2009) }\end{array}$ \\
\hline Participación de terceros involucrados & Akhmadova y Sadulayeva vs. Rusia (2007) \\
\hline
\end{tabular}

Fuente: Elaboración propia 


\section{Normatividad interna de los Estados demandados}

En lo que respecta al derecho interno, ninguna de las sentencias estudiadas evidencia que existiera normatividad interna que busque evitar la desaparición de personas, o que sancione a quienes cometan estos actos. Tampoco se evidencia que el avance jurisprudencial de la Corte facilitara la creación de leyes o normatividad que impulsara a los Estados a regular este tipo de situaciones o a crear medidas para investigarlas y sancionarlas oportunamente (ver Tabla 6).

Por otro lado, el análisis de las sentencias permite observar que el sistema legislativo de la mayoría de los países en los casos analizados, son especialmente garantes de los derechos a la vida, la dignidad, la integridad y la libertad física. Además, existen disposiciones relacionadas con el deber de indemnización por las acciones cometidas por agentes estatales, los delitos, el procedimiento penal y las circunstancias bajo las cuales se pueden limitar derechos. De igual modo, es muy importante el análisis de los casos de Rusia y Turquía, donde la presencia de decretos o leyes que regulan la lucha contra el terrorismo facilitaban los ambientes para que las autoridades públicas se extralimitaran en el uso de la fuerza y no rindieran cuentas a otro tipo de entes gubernamentales (ver Tabla 6).

Con base a lo anterior, se destacan las siguientes situaciones relacionadas con la normatividad interna de los Estados:

En los casos de Varnava, Janowiec y Gutiérrez Dorado, la Corte es consciente de que la legislación nacional al momento de los hechos no obligaba a los Estados a garantizar la no comisión de actos de desaparición contra la población militar o civil y en consecuencia, la protección auténtica de derechos humanos (Varnava vs. Turquia, 2009) ( Janowiec and others vs. Rusia, 2013) (Antonio Gutierrez Dorado y Carmen Dorado vs. España, 2012).

Es de especial cuidado el contexto normativo de las desapariciones presentadas en los casos de Turquía y Rusia, debido a que ambos países poseen decretos y leyes especiales para la lucha contra el terrorismo, el decreto y manejo de Estados de Emergencia, el manejo de información secreta (de inteligencia y contrainteligencia principalmente) y la materialización de situaciones o información que constituyen secreto de Estado y que facultan a las autoridades para arremeter y agredir a la población civil, atentar en su contra, vulnerarles derechos, dilatar o impedir la idónea ejecución de las investigaciones penales, civiles o administrativas y retrasar trámites jurisdiccionales. (Timurtas vs. Turquía, 2000) (Kurt vs. Turquía, 1998) (Orhan vs. Turquía, 2002) (Ipek vs. Turquía, 2004) (Imakayeva vs. Rusia, 2007) (Khadzhialiyev y otros vs. Rusia, 2009). 
En el caso Gutiérrez Dorado, es de importancia la creación en la década de 1970 de una ley para eximir de responsabilidad penal a todos los miembros del régimen que cometieron delitos, actos de represión (Antonio Gutiérrez Dorado y Carmen Dorado vs. España, 2012), esta ley no permite el abordaje de este tipo de situaciones ante instrumentos jurisdiccionales de orden nacional, más sin embargo, en la actualidad dichos actos son merecedores de ser investigados y sancionados, de acuerdo con los valores y estándares contemporáneos del derecho internacional de los derechos humanos.

Tabla 6

Normatividad de los Estados en los casos estudiados

\begin{tabular}{|c|c|}
\hline $\begin{array}{c}\text { Normatividad interna } \\
\text { (tomada de las sentencias) }\end{array}$ & Estados con dicha normatividad \\
\hline Leyes contra fenómenos de desaparición & $\begin{array}{l}\text { Ningún Estado en las sentencias } \\
\text { estudiadas }\end{array}$ \\
\hline $\begin{array}{l}\text { Medidas de reparación por contravenciones de } \\
\text { agentes estatales }\end{array}$ & Turquía en 12 sentencias \\
\hline $\begin{array}{l}\text { Ley penal consagra normas contra la privación } \\
\text { arbitraria de la libertad, la tortura y los malos tratos }\end{array}$ & $\begin{array}{l}\text { Turquía en } 12 \text { sentencias } \\
\text { Rusia en } 7 \text { sentencias } \\
\text { Macedonia en } 1 \text { sentencia }\end{array}$ \\
\hline Normatividad para la lucha contra el terrorismo & $\begin{array}{l}\text { Turquía en } 12 \text { sentencias } \\
\text { Rusia en } 7 \text { sentencias }\end{array}$ \\
\hline $\begin{array}{l}\text { Leyes que favorecen el secreto de Estado y la } \\
\text { no publicidad de ciertos procedimientos de } \\
\text { inteligencia y lucha contra el terrorismo }\end{array}$ & Rusia en 8 sentencias \\
\hline $\begin{array}{l}\text { Protección constitucional a la vida, la libertad y } \\
\text { la integridad personal }\end{array}$ & $\begin{array}{l}\text { Turquía en } 12 \text { sentencias } \\
\text { Rusia en } 7 \text { sentencias } \\
\text { Ucrania en } 1 \text { sentencia } \\
\text { España en } 1 \text { sentencia } \\
\text { Macedonia en } 1 \text { sentencia }\end{array}$ \\
\hline $\begin{array}{l}\text { Leyes para eximir responsabilidad por actos } \\
\text { ilícitos de agentes del Estado (casos especiales } \\
\text { por antigüedad) }\end{array}$ & $\begin{array}{l}\text { Rusia en } 1 \text { sentencia } \\
\text { España en } 1 \text { sentencia }\end{array}$ \\
\hline $\begin{array}{l}\text { Normatividad para investigar y reparar victimas } \\
\text { de graves violaciones a los Derechos Humanos } \\
\text { (casos especiales por antigüedad) }\end{array}$ & $\begin{array}{l}\text { Rusia en } 1 \text { sentencia } \\
\text { España en } 1 \text { sentencia }\end{array}$ \\
\hline
\end{tabular}

Fuente: Elaboración propia

\section{Respuesta de los Estados ante el conocimiento de la desaparición}

Se puede evidenciar que en los casos de desaparición forzada los Estados tienden a negar los hechos como un primer factor de respuesta, esta negativa suele estar acompañada de falta de comunicación, respuestas objetivas o verídicas cuando 
los familiares de las víctimas acuden ante las autoridades a solicitar información sobre el paradero de sus seres queridos y familiares. Adicionalmente, en todos los casos estudiados el Estado moviliza su aparato jurisdiccional de algún modo para investigar, en el campo penal o administrativo, cual ha sido la suerte de los desaparecidos. Sin embargo, existe una constante en las sentencias, donde se evidencia la negativa por parte de las autoridades a colaborar, a surtir con buen éxito las investigaciones, agilizarlas o evitar que sean dilatorias.

En relación con las medidas tomadas en nombre del Estado al momento de la desaparición, se destacan las relacionadas con los siguientes casos:

En las sentencias de Timurtas, Cakici y Kurt contra la república de Turquía, con posterioridad a las desapariciones, las autoridades públicas difamaron a los desaparecidos sin ningún elemento probatorio, al decir que ellos pertenecían o se habían unido a las fuerzas insurgentes y que si sus familiares querían saber su paradero tenían que contactar con estos grupos (Timurtas vs. Turquía, 2000) (Çakici vs. Turquía, 1999) (Kurt vs. Turquía, 1998).

En casos como Timurtas, Kurt, Avsar contra la república de Turquía e Imakayeva contra la república de Rusia se presentaron fenómenos de amenazas o acoso a los familiares de las víctimas, y en estos casos, el Estado en cuestión no tomó las medidas necesarias para evitar que dichos actos continuaran y no se pusiera en peligro otros derechos (Imakayeva vs. Rusia, 2007) (Avsar vs. Turquía, 2002) (Timurtas vs. Turquía, 2000) (Kurt vs. Turquía, 1998).

Son destacables los casos de Mahmut Kaya, Salman, Cakici contra la república de Turquía ya que presentan hechos donde la víctima muere con posterioridad a su detención y su cadáver es encontrado antes de que sus familiares acudan al Sistema Europeo de Derechos Humanos. En estas situaciones, el Estado deja de asumir las investigaciones en relación con una desaparición y afronta los hechos simplemente como un homicidio, lo cual limita la capacidad jurisdiccional de las autoridades encargadas y dilata más los procesos jurisdiccionales. (Mahmut Kaya vs. Turquía, 2000) (Salman vs. Turquía, 2000) (Çakici vs. Turquía, 1999).

Los casos contra la república de Rusia son de bastante cuidado, ya que la normatividad interna rusa y el contexto bélico en Chechenia facilitaba que a los desaparecidos fueran tomados como insurgentes y terroristas y en consecuencia, que se tomara como secreto de Estado todas las acciones que se cometían en la zona de conflicto. (Sadulayeva vs. Rusia, 2010) (Khadzhialiyev y otros vs. Rusia, 2009) (Yusupova y Zaurbekov vs. Rusia, 2004). 


\section{Conclusiones}

En primer lugar, es importante mencionar que efectivamente se evidenció una evolución jurisprudencial de la ECHR a lo largo del tiempo, cuyos cambios paulatinos han repercutido en la declaratoria de responsabilidad de los Estados. En este sentido, la evolución del alto Tribunal ha sido progresivamente garantista y favorable respecto al reconocimiento de responsabilidad internacional del Estado por actos o hechos en perjuicio de las víctimas. Sin embargo, los pronunciamientos del tribunal no se alejan de aquellos factores determinantes de la competencia o de la apreciación de la prueba.

También, existe una falta de consenso en el abordaje que se hace en Europa sobre esta problemática, las medidas que se deben adoptar y los mecanismos para prevenir este delito; se puede decir que ello es debido a la ausencia de un pronunciamiento regional sobre la desaparición forzada y los elementos normativos bajo los cuales se aborda este fenómeno, lo cual, en consecuencia, lleva al tribunal Europeo a analizar los casos desde la óptica de otros instrumentos internacionales propios de sistemas ajenos o alejados del Sistema Europeo de Derechos Humanos.

Por otro lado, es claro que las desapariciones forzadas en Europa se tienen que analizar desde una perspectiva internacional por la gravedad y el alcance de los conflictos en los cuales se desarrolla el delito; también, el estudio de este fenómeno debe estar abierto a analizar situaciones que se salen del marco de competencia de los tribunales europeos vigentes, pero que involucran graves violaciones a los derechos humanos.

Finalmente, sostenemos que la ausencia de un estatuto o una definición clara sobre el fenómeno de la desaparición forzada en la jurisprudencia del Sistema Europeo se debe a que, por lo general, los directos responsables de los casos de las desaparición no son plenamente encontrados y criminalizados; en algunos casos (por ejemplo en Gongadze o Kadzhdilayev) la desaparición es tomada más como un fenómeno criminal propio de los actos que realizan los particulares dentro de la jurisdicción interna del país. Sin embargo, el elemento clave que permite inferir la ausencia de elementos normativos en el nivel internacional sobre este delito, es el hecho de tratar con un fenómeno relativamente nuevo, de bajo impacto y repetición en el nivel europeo. 


\section{Referencias}

Akdeniz vs. Turquía, 23954/94 (Corte Europea de Derechos Humanos, 31 de mayo de 2001).

Akhmadova y Sadulayeva vs. Rusia, 40464/02 (Corte Europea de Derechos Humanos, 12 de noviembre de 2007).

Amnistía Internacional, CAGEPRISIONERS, Human Rights Watch, Center For Constitutional Rights, Reprieve, CHR \& GJ. (2007). Sin rastro oficial, responsabilidad de Estados Unidos en las desapariciones forzadas de la guerra contra el terror. Obtenido de Amnistía Internacional. Recuperado de https://www.es.amnesty.org/uploads/media/25109307_ext_WoT__Sin_rastro_oficial_.pdf

Antonio Gutiérrez Dorado y Carmen Dorado vs. España, 30141/09 (Corte Europea de Derechos Humanos, 27 de marzo de 2012).

Asamblea General de la Organización de las Naciones Unidas. (18 de diciembre de 1992). Declaración sobre la protección de todas las personas contra las desapariciones forzadas.

Avsar vs. Turquía, 25657/94 (Corte Europea de Derechos Humanos, 27 de marzo de 2002).

Çakici vs. Turquía, 23657/94 (Corte Europea de Derechos Humanos, 08 de julio de 1999).

Chelysheva, O. (2006). El Conflicto de Chechenia MAPAMUNDI DE CONFLICTOS BALCANES/CAUCASO. Barcelona: Jornadas Internacionales, quien no tiene memoria no tiene futuro.

Chinchon Álvarez, J. (2015). Las desapariciones forzadas en la jurisprudencia del Tribunal Europeo de Derechos Humanos. En M. y CASADO, Desapariciones forzadas de niños en Europa y Latinoamérica. Del Convenio de la ONU a las búsquedas através del ADN (págs. 341-359). Barcelona: UNESCO-Cátedra de Bioética de la Universitat de Barcelona y Observatori de Bioètica i Dret.

Chipre vs. Turquía, 25781/94 (Corte Europea de Derechos Humanos, 10 de mayo de 2001).

Claude, O. (2010). A Comparative Approach to Enforced Disappearences In The Inter-American Court Of Human Rights and The European Court Of Human Rights. Intercultural Human Rights Law Review, 407-462.

Dijkstra, P., Klann, H., Ruimschotel, R., \& Wijnkoop, M. (2002). Enforced Disappearances As Continuing Violations. Amsterdam: AMSTERDAM INTERNATIONAL LAW CLINIC.

El-Masri vs. The Former Yugoslav Republic of Macedonia, 39630/09 (Corte Europea de Derechos Humanos, 13 de diciembre de 2012). 
Erener, S. (2015). Competing Standards on the Definition of Enforced Disappearance A victims-oriented perspective for national implementation. Lund: Master Thesis, Lund University.

Ertak vs. Turquía, 20764/92 (Corte Europea de Derechos Humanos, 09 de mayo de 2000).

Finucane, B. (2011). Enforced Disappearance as a Crime Under International Law: A Neglected Origin in the Laws of War. Yale Journal of International Law, 171-195.

Gongadze vs. Ucrania, 34056/02 (Corte Europea de Derechos Humanos, 08 de febrero de 2006).

Imakayeva vs. Rusia, 7615/02 (Corte Europea de Derechos Humanos, 09 de febrero de 2007).

Ipek vs. Turquía, 25760/94 (Corte Europea de Derechos Humanos, 17 de mayo de 2004).

Janowiec and others vs. Rusia, 55508/07 and 29520/09 (Corte Europea de Derechos Humanos, 21 de octubre de 2013).

Khadzhialiyev y otros vs. Rusia, 3013/04 (Corte Europea de Derechos Humanos, 06 de abril de 2009).

Kurt vs. Turquía, 15/1997/799/1002 (Corte Europea de Derechos Humanos, 25 de mayo de 1998).

Kyriakou, N. (2012). An affront to the conscience of humanity: enforced disappearance in international human rights law. Florencia: European University Institute.

Magomed Musayev y otros vs. Rusia, 8979/02 (Corte Europea de Derechos Humanos, 06 de abril de 2009).

Mahmut Kaya vs. Turquía, 22535/93 (Corte Europea de Derechos Humanos, 20 de marzo de 2000).

Malsagova y otros vs. Rusia, 27244/03 (Corte Europea de Derechos Humanos, 06 de noviembre de 2009).

Orhan vs. Turquía, 25656/94 (Corte Europea de Derechos Humanos, 06 de noviembre de 2002).

Organizacion de los Estados Americanas. (09 de junio de 1994). Convención Interamericana Sobre Desaparicion Forzada de Personas. Belem Do Para, Brasil.

Sadulayeva vs. Rusia, 38570/05 (Corte Europea de Derechos Humanos, 04 de octubre de 2010).

Salman vs. Turquía, 21986/93 (Corte Europea de Derechos Humanos, 27 de junio de 2000).

Tanis y otros vs. Turquía, 65899/01 (Corte Europea de Derechos Humanos, 30 de noviembre de 2005).

Timurtas vs. Turquía, 23531/94 (Corte Europea de Derechos Humanos, 13 de junio de 2000). 
Varnava vs. Turquía, 16064/90, 16065/90, 16066/90, 16068/90, 16069/90, 16070/90, 16071/90, 16072/90 and 16073/90 (Corte Europea de Derechos Humanos, 18 de septiembre de 2009).

Yusupova y Zaurbekov vs. Rusia, 22057/02 (Corte Europea de Derechos Humanos, 06 de abril de 2004).

Zorrilla, J. A. (2014). Los Kurdos. Instituto Español de Estudios Estrategicos.

Recibido: 10/8/2018

Aceptado: 2/5/2019 
